\title{
EVALUATION OF THE IMPACT OF HYDROSTATIC PRESSURE AND LODE ANGLE ON THE STRENGTH OF THE ROCK MASS BASED ON THE HOEK-BROWN CRITERION
}

\author{
HALINA MARCZAK \\ Mechanical Faculty, Lublin University of Technology, \\ ul. Nadbystrzycka 36, 20-618 Lublin, Poland, e-mail: h.marczak@pollub.pl
}

\begin{abstract}
Determination of the global uniaxial compressive strength of rock mass on the basis of the Hoek-Brown failure criterion requires knowledge of the strength parameters: cohesion and the angle of internal friction. In the conventional method for the determination of these parameters given by Balmer, they are expressed by the minimum principal stress. Thus, this method does not allow for the assessment of an impact of hydrostatic pressure and stress path on the value of cohesion, friction angle and global uniaxial compression of rock mass. This problem can be eliminated by using the Hoek-Brown criterion expressed by the invariants of the stress state. The influence of hydrostatic pressure and the Lode angle on the strength parameters of the rock mass was analysed.
\end{abstract}

Key words: generalized Hoek-Brown failure criterion, equivalent cohesion, equivalent friction angle, the global strength, invariant stress

\section{INTRODUCTION}

A limit state in the rock mass arises when the stress in it reaches certain limits. This condition causes destruction as a result of brittle or ductile fracture. Depending on the values of stress in the material, the speed of stress or strain increase and the temperature values, the same material can act like a ductile (malleable) or brittle material. Research conducted, among others, by Paterson [16], Mogi [13], [14] and Kwaśniewski [11] showed that the toughness of rock increases with increasing circular pressure $\left(p=\sigma_{2}=\sigma_{3}\right)$ in the conventional triaxial compression, with an increase in the minimum principal stress $\sigma_{3}$, and/or by reducing the value of the intermediate stress $\sigma_{2}$ under triaxial compression conditions $\left(\sigma_{1} \neq \sigma_{2} \neq \sigma_{3}\right)$, and also with the temperature increasing. In addition, the ductility of rocks increasing with decreasing pore pressure and strain rate. Therefore, it is necessary to formulate the boundary conditions so that they express well the impact of relevant factors on the strength of the boundary rocks. There are many criteria for strength, differentiated by the theories of origin, i.e., the theories of stress, deformation, energy and statistical theories of slots [11]. There are also purely empirical strength criteria developed on the basis of various rocks in various states of stress. The description of these criteria are included in the works by Kwaśniewski [11] and Brady and Brown [2]. Empirical criteria are one of the directions of research in the destruction process in the rock mass. The solutions obtained with consideration given to empirical criteria of strength solutions which describe the behaviour of the rock can be particularly useful in studies of the rock mass as a discontinuous medium. Due to the fact that the rock mass should be seen as a discontinuous medium and only relatively rarely as a continuum, the significance of these solutions increases.

Currently, one of the empirical criteria used is a version of the Hoek-Brown failure criterion developed for uncracked and cracked rock mass. The characteristics and guidelines for the use of the Hoek-Brown criterion are presented in the work of Hoek [5], [8].

Hoek and Brown [6] introduced the concept of global uniaxial compression $\sigma_{c m}$ of a rock mass that meets the Hoek-Brown failure criterion. Its value is determined according to the Coulomb-Mohr relationship

$$
\sigma_{c m}=\frac{2 c \cos \varphi}{1-\sin \varphi}
$$

where 
$c$ - cohesion of the rock mass as Hoek-Brown material,

$\varphi$ - internal fraction angle for the rock mass as Hoek-Brown material.

In the conventional method of determining $c, \varphi$ and $\sigma_{c m}$, based on the theory of Balmer [1], the influence of the minimum principal stress on the values of these parameters is taken into account, but the impact of the intermediate principal stress, the hydrostatic pressure and the stress path is not considered.

Lee et al. [12] proposed a method that eliminates the inconvenience of conventional solutions by making use of invariants in the state of stress. Appropriate calculations were made to assess whether it is important to take into account the hydrostatic pressure and stress path in the solution determining the parameters $c, \varphi$ and $\sigma_{c m}$. Based on the results of calculations an analysis and assessment of the effects of hydrostatic pressure and the Lode angle on global uniaxial compressive strength of rock were made.

\section{THE METHOD \\ OF DETERMINING THE COHESION AND INTERNAL FRICTION ANGLE OF THE ROCK MASS}

The angle of internal friction and cohesion, these being the parameters needed to determine the global compressive strength of the rock mass, can be determined by the method of the tangent to the envelope of the largest Mohr's circles, which is a graphic image of the Mohr limit state condition.

According to Mohr's theory, reaching the limit state of the material depends on shear stress occurring on the surfaces of destruction. This condition can be expressed as

$$
|\tau|-f\left(\sigma_{n}\right)=0
$$

where

$|\tau|$ - absolute value of the shear stress,

$f\left(\sigma_{n}\right)$ - the function of normal stress acting on the surface of the destruction.

Equation (2) is determined experimentally. $\sigma_{n}$ and $\tau$ values fulfilling equation (2) depend on the difference of normal stresses $\sigma_{1}$ and $\sigma_{3}$. The points fulfilling the equation $|\tau|=f\left(\sigma_{n}\right)$ form an envelope of Mohr's circles in the coordinate system $\left(\sigma_{n}, \tau\right)$ (Fig. 1).

The angle between the plotted tangent to the envelope and the abscissa is the angle of internal friction. The $Y$ intercept of the tangent with the ordinate axis corresponds to the value of consistency. The method of tangent to the Mohr envelope is a biased method. More detailed designation of these parameters can be achieved with computational methods. One such method uses the Balmer solution.

Balmer [1] gave a relationship for the setting of the values of shear stress and normal stress acting in the plane of destruction (shear), which have the following form

$$
\begin{gathered}
\tau_{f}=\left(\sigma_{n f}-\sigma_{3}\right) \sqrt{\frac{\partial \sigma_{1}}{\partial \sigma_{3}}}, \\
\sigma_{n f}=\sigma_{3}+\frac{\sigma_{1}-\sigma_{3}}{\frac{\partial \sigma_{1}}{\partial \sigma_{3}}+1},
\end{gathered}
$$

where

$\tau_{f}, \sigma_{n f}-$ normal and tangential stress at the surface of destruction,

$\sigma_{1}, \sigma_{3}-$ principal stresses.

In order to determine the instantaneous values of the angle of internal friction $\varphi_{i}$ (for data values $\sigma_{1}$ and $\sigma_{3}$ ) advantage is taken of the fact that the section plane is inclined to the direction of the minimum principal stress $\sigma_{3}$ at the angle $\alpha$ of [9]

$$
\alpha= \pm\left(45^{\circ}+\frac{\varphi_{i}}{2}\right)
$$

Angle $\varphi_{i}$ is described by the relationship obtained from the transformation of equation (5) for positive values of the angle $\alpha$

$$
\varphi_{i}=2 \alpha-90^{\circ} .
$$

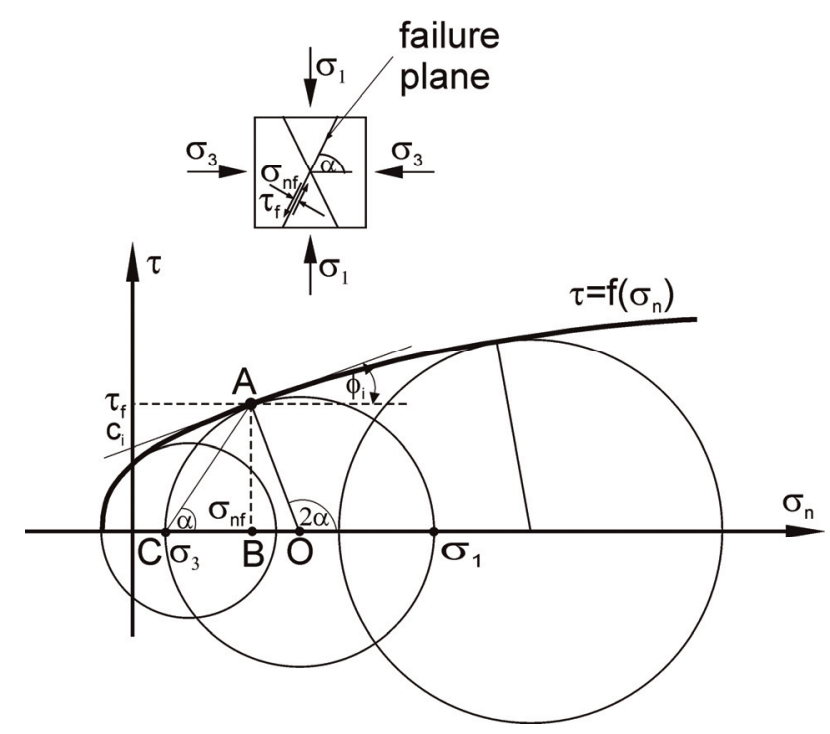

Fig. 1. The envelope of Mohr's circles expressing the limit state of the material [12] 
Stress $\tau_{f}$ and $\sigma_{n f}$ occurring in the plane of the specified angle $\alpha$ are shown by point A on the Mohr circle (Fig. 1). The Mohr's circle displayed corresponds to the limit values of the principal stresses $\sigma_{1}$ and $\sigma_{3}$.

Figure 1 implies that

$$
\operatorname{tg} \alpha=\frac{A B}{B C} .
$$

After taking into account equation (7), the expressions for the lengths of segments $\mathrm{AB}$ and $\mathrm{BC}$, resulting from Fig. 1, this equation takes the form

$$
\operatorname{tg} \alpha=\frac{\tau_{f}}{\frac{\sigma_{1}+\sigma_{3}}{2}-\sigma_{n f}} .
$$

Applying relationships (3) and (4) in formula (8) leads to

$$
\alpha=\operatorname{arctg}\left(\sqrt{\frac{\partial \sigma_{1}}{\partial \sigma_{3}}}\right) .
$$

Instantaneous value cohesion $c_{i}$, i.e., for the values of $\sigma_{1}$ and $\sigma_{3}$, is determined by the tangent to the Mohr envelope using the relationship resulting from the condition of the Coulomb-Mohr strength

$$
c_{i}=\tau_{f}-\sigma_{n f} \operatorname{tg} \varphi_{i} .
$$

For a rock meeting the Hoek-Brown generalisation, the failure criterion is described the relationship

$$
\sigma_{1}=\sigma_{3}+\sigma_{c}\left(m_{b} \frac{\sigma_{3}}{\sigma_{c}}+s\right)^{a}
$$

where

$\sigma_{1}, \sigma_{3}$ - principal stresses,

$\sigma_{c}$ - strength of uncracked rock to uniaxial compression,

$m_{b}, s, a$ - material constants for the rock mass [8], shear stress $\tau_{f}$ and normal stress $\sigma_{n f}$ are calculated from the relationship

$$
\tau_{f}=\frac{\sigma_{c}\left(m_{b} \frac{\sigma_{3}}{\sigma_{c}}+s\right)^{a}}{2+m_{b} a\left(m_{b} \frac{\sigma_{3}}{\sigma_{c}}+s\right)^{a-1}} \sqrt{1+m_{b} a\left(m_{b} \frac{\sigma_{3}}{\sigma_{c}}+s\right)^{a-1}},
$$

$$
\sigma_{n f}=\sigma_{3}+\frac{\sigma_{c}\left(m_{b} \frac{\sigma_{3}}{\sigma_{c}}+s\right)^{a}}{2+m_{b} a\left(m_{b} \frac{\sigma_{3}}{\sigma_{c}}+s\right)^{a-1}} .
$$

Hoek-Brown's material constants are defined by the following relationships

$$
\begin{gathered}
m_{b}=m_{i} \exp \left(\frac{G S I-100}{28-14 D}\right), \\
s=\exp \left(\frac{G S I-100}{9-3 D}\right), \\
a=\frac{1}{2}+\frac{1}{6}\left(\exp \left(-\frac{G S I}{15}\right)-\exp \left(-\frac{20}{3}\right)\right),
\end{gathered}
$$

where

$m_{i}-$ constant for intact rock [7],

GSI - Geological Strength Index,

$D$ - coefficient depending on the type and extent of violations of the rock mass; for weak rock mined with explosives $D=0$, for rock strengths mined with a mechanical miner $D=1$ [8].

The angle $\alpha$ is calculated from the following equation obtained by formula (9) after substitution of $\frac{\partial \sigma_{1}}{\partial \sigma_{3}}$ with the expression resulting from the HoekBrown criterion

$$
\alpha=\operatorname{arctg}\left(\sqrt{1+m_{b} a\left(m_{b} \frac{\sigma_{3}}{\sigma_{c}}+s\right)^{a-1}}\right)
$$

\section{THE HOEK-BROWN CRITERION EXPRESSED BY THE INVARIANTS OF THE STRESS STATE AND THE LODE ANGLE}

The Hoek-Brown failure criterion (11) ignores the effect of the intermediate principal stress $\sigma_{2}$ on the strength of the material. This problem can be solved by expressing the condition endurance using invariants of the stress state, such as $p, q$ and $\Theta$ invariants. These invariants constitute the principal stresses in the cylindrical coordinate axes, while axis $q$ and angle $\Theta$ belong to the deviatoric plane (given in the equation $\sigma_{1}+\sigma_{2}+\sigma_{3}=$ const, in which $p=$ const, $q=$ var), which is perpendicular to the hydrostatic axis $\sigma_{1}=\sigma_{2}$ 


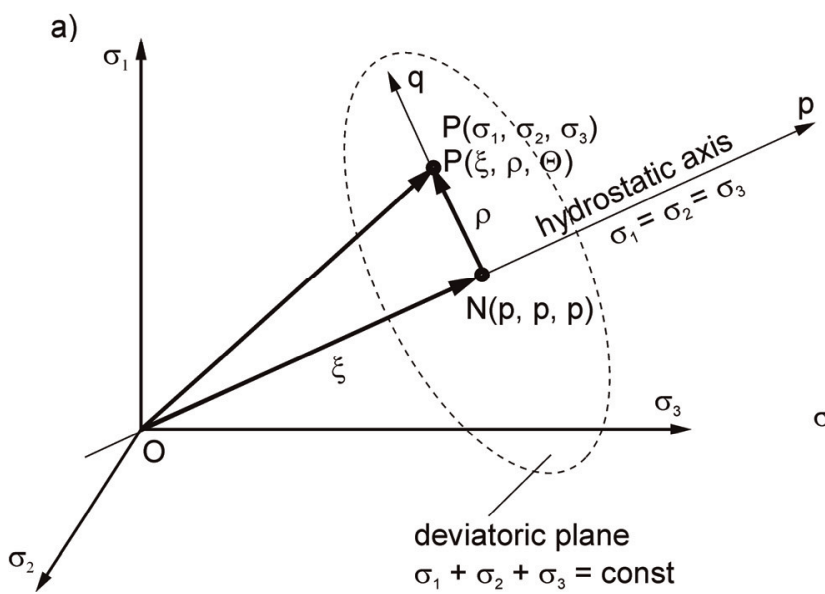

b)

Fig. 2. The state of tension in the principal stress in the Cartesian coordinate system (a) and the deviatoric plane (b) [3]

$=\sigma_{3}$ and inclined to three principal stress axes in the same angle. Thus, the stress state in the space of principal stresses can be represented in a Cartesian coordinate system $\mathrm{P}\left(\sigma_{1}, \sigma_{2}, \sigma_{3}\right)$ or cylindrical $\mathrm{P}(p, q, \Theta)$ (Fig. 2) [3].

Cartesian vector $\overline{O P}$ has components $\overline{O P}_{k}=$ $\left[\sigma_{1}, \sigma_{2}, \sigma_{3}\right]$ (Fig. 2), while for a cylindrical arrangement $\overline{O P}_{c}=\left[\sqrt{3} p, \sqrt{\frac{2}{3}} q, \Theta\right]$ or $\overline{O P}_{c}=[\xi, \rho, \Theta][10]$, where $\xi=\sqrt{3} p$ and $\rho=\sqrt{\frac{2}{3}} q$ are respectively the hydrostatic and deviatoric stress state vector components in the principal stress space [4].

Invariant $p$ (meaning stress or hydrostatic pressure) is given by

$$
p=\frac{I_{1}}{3}
$$

where $I_{1}-$ the first invariant of the stress tensor.

Invariant $q$ (stress intensity) is calculated from the following relationship

$$
q=\sqrt{3 J_{2}}
$$

where $J_{2}$ - the second invariant of deviatoric stress tensor.

The angle $\Theta$ (Lode angle) determines the position of the point P (Fig. 2) in the deviatoric plane distant from the coordinate origin $\left(\sigma_{1}, \sigma_{2}, \sigma_{3}\right)$ by the value of $\xi$, where $\theta$ is calculated from

$$
\Theta=\frac{1}{3} \arccos \left(\frac{3 \sqrt{3} J_{3}}{2 J_{2}^{3 / 2}}\right) ; \quad 0 \leq \Theta \leq \frac{\pi}{3}
$$

where $J_{3}-$ the third invariant of deviatoric stress tensor.
The angle $\Theta$ and the relationship between $\Theta, J_{2}$ and $J_{3}$ were first given by Nayak and Zienkiewicz [15].

Overall, the value of Lode angle indicates whether the stress state corresponds more to triaxial compression conditions $(\Theta=0)$, or to triaxial exten$\operatorname{sion}\left(\Theta=60^{\circ}\right)$.

The principal stresses and invariants $(\xi, \rho, \Theta)$ depend on the relationships:

$$
\left[\begin{array}{l}
\sigma_{1} \\
\sigma_{2} \\
\sigma_{3}
\end{array}\right]=\frac{1}{\sqrt{3}}\left[\begin{array}{l}
\xi \\
\xi \\
\xi
\end{array}\right]+\sqrt{\frac{2}{3}} \rho\left[\begin{array}{l}
\cos \Theta \\
\cos \left(\Theta-\frac{2}{3} \pi\right) \\
\cos \left(\Theta+\frac{2}{3} \pi\right)
\end{array}\right] .
$$

The generalised version of the Hoek-Brown strength criterion (11) expressed by invariants takes the form

$$
\begin{gathered}
{\left[\sqrt{2} \rho \sin \left(\Theta+\frac{\pi}{3}\right)\right]^{\frac{1}{a}}} \\
=\sigma_{c}^{\frac{1-a}{a}}\left[m_{b}\left(\frac{1}{\sqrt{3}} \xi+\sqrt{\frac{2}{3}} \rho \cos \left(\Theta+\frac{2 \pi}{3}\right)\right)\right]+\sigma_{c^{a}}^{\frac{1}{a}} s .
\end{gathered}
$$

Substituting $\sigma_{3}$ in relationships (12), (13) and (17) with equation 3 resulting from relationships (21), parameters $p$ and $\Theta$ are introduced. Thus, the parameters calculated on the basis of the changed equations (12), (13) and (17): cohesion, internal friction angle and global compressive strength of the rock will depend on hydrostatic pressure and the Lode angle. 


\section{EFFECT OF MEAN STRESS, LODE ANGLE AND GSI FOR INSTANTANEOUS VALUE GLOBAL COMPRESSIVE STRENGTH OF THE ROCK MASS}

Assuming that the rock mass fulfils the generalized Hoek-Brown criterion, and assuming the parameter values of the criterion, i.e., $m_{i}=10, \sigma_{c}=70 \mathrm{MPa}$ and $D=0$, the influence of hydrostatic pressure, the Lode angle and GSI for instantaneous value global compressive strength rock massif $\sigma_{c m i}$ were calculated according to the formula:

$$
\sigma_{c m_{i}}=\frac{2 c_{i} \cos \varphi_{i}}{1-\sin \varphi_{i}}
$$

where $c_{i}, \varphi_{i}$ - the instantaneous cohesion and internal friction angle for the centre meeting the Hoek-Brown criterion respectively (11).

Figure 3 shows the change in the instantaneous value of $\varphi_{i}$ angle of internal friction, instantaneous cohesion $c_{i}$ and instantaneous compressive strength of the rock mass $\sigma_{c m i}$ depending on the hydrostatic pressure $p$ for the conditions similar to the triaxial compression $\left(\sigma_{1}>\sigma_{2}=\sigma_{3}, \Theta=0^{\circ}\right)$. Figure 3 (and subsequent figures) present only the results of calculations obtained for the principal stress $\sigma_{1}>0$ (compression) and $\sigma_{2} \geq 0$, and $\sigma_{3} \geq 0$. However, the results of calculations obtained when at least one of the principal stresses is less than zero (extension) were not included. The calculations show that the instantaneous value of the angle of internal friction decreases expo-

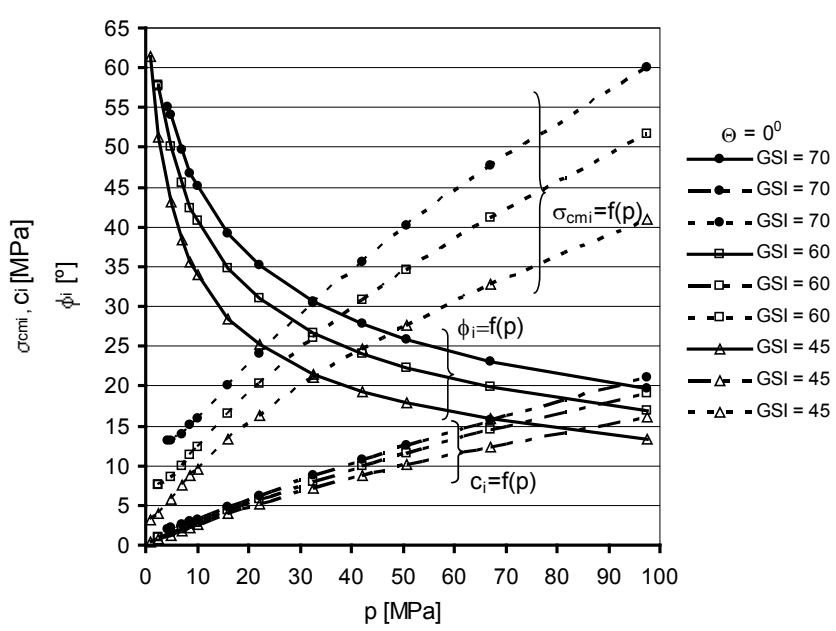

Fig. 3. Dependence of instantaneous global value of compressive strength $\sigma_{c m i}$, cohesion $c_{i}$ and angle of internal friction $\varphi_{i}$ of the rock mass on the value GSI and hydrostatic pressure $p$ nentially with the increase in hydrostatic pressure $p$. Instantaneous values of cohesion grow non-linearly with increasing values of $p$. The instantaneous global value of the compressive strength of the rock mass exhibits a non-linear increase with increasing hydrostatic pressure, the growth rate being high. GSI has a clear impact on the changes of the parameters analysed. For given $p$-values, higher values of GSI correspond to higher values of the analysed parameters.

Figure 4 shows, for the values of GSI 70 and 45, and values of the Lode angle $\Theta=0^{\circ}, \Theta=30^{\circ}$ and $\Theta=60^{\circ}$, the changing output of compressive strength of the rock mass, depending on the hydrostatic pressure.
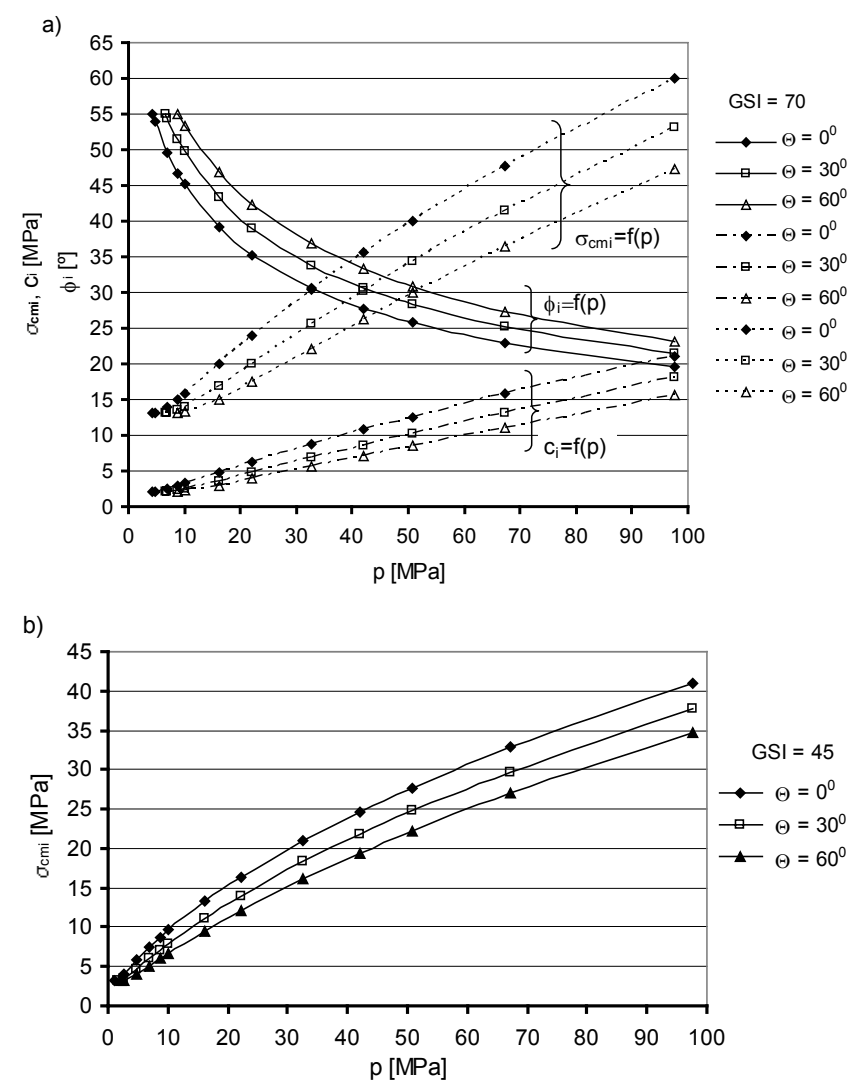

Fig. 4. Dependence of global compressive strength $\sigma_{c m i}$, cohesion $c_{i}$ and internal friction angle $\varphi_{i}$ of the rock mass on the Lode angle $\Theta$ and the hydrostatic pressure $p$; (a) $G S I=70$, (b) $G S I=45$ (only for $\sigma_{c m i}$ )

The analysis of the angle of $\Theta=0^{\circ}, \Theta=30^{\circ}, \Theta=$ $60^{\circ}$ is illustrated by the conditions of triaxial compression $\left(\sigma_{1}>\sigma_{2}=\sigma_{3}\right)$, pure shear $\left(\sigma_{2}=\left(\sigma_{1}+\sigma_{3}\right) / 2\right)$ and triaxial extension $\left(\sigma_{1}=\sigma_{2}>\sigma_{3}\right)$, respectively.

For both values of GSI the increase in the value of the Lode angle corresponds to a temporary decline in the global value of the compressive strength of the rock mass $\sigma_{c m i}$ for the same value of hydrostatic pressure $p$. The same relationship is manifested in instantaneous cohesion. In contrast, the temporary internal 
friction angle reaches the highest value for the Lode angle of $60^{\circ}$. The rate of change of the instantaneous resistance to compressive strength of the rock mass depending on the Lode angle is greater for $G S I=70$ (Fig. 4a) compared with the value of GSI index $=45$ (Fig. 4b). The conclusion is that the Lode angle has less impact on weaker rock massif (lower GSI value).

The changes of the Lode angle of the analysed parameters and GSI for hydrostatic pressure $p=42 \mathrm{MPa}$ are shown in Fig. 5.
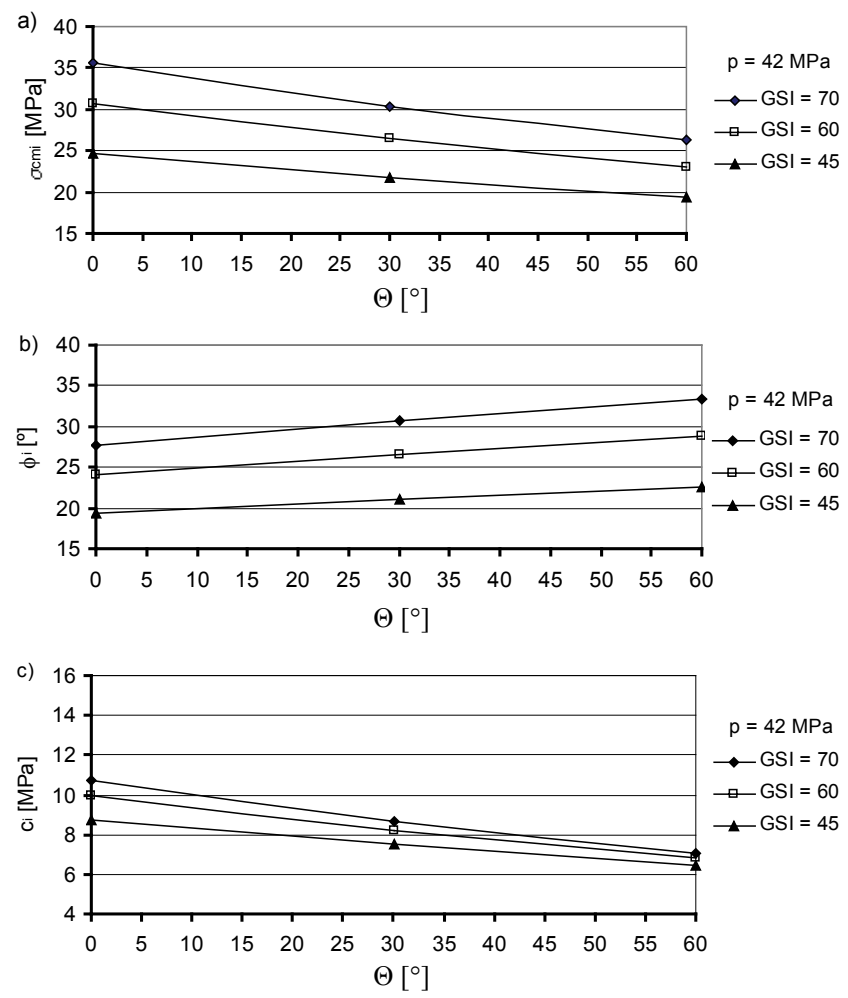

Fig. 5. Influence of the Lode angle $\Theta$ in deviatoric plane on a global compressive strength $\sigma_{c m i}$ (a), the angle of internal friction $\varphi_{i}(\mathrm{~b})$ and cohesion $c_{i}(\mathrm{c})$ of the rock mass

The $\sigma_{c m i}$ value for $\Theta=0^{\circ}$ and for $G S I=45$ is about $31 \%$ lower than the value obtained for $G S I=70$ with unchanged values of other parameters. For higher values of the Lode angle a weaker impact of GSI on the value of $\sigma_{c m i}$ is observed.

The instantaneous angle of internal friction for the value $p=42 \mathrm{MPa}$ increases with increasing angle of $\Theta$, whereas the cohesion is reverse (Fig. $5 \mathrm{~b}$ and $5 \mathrm{c}$ ). The differences in the values of angle $\varphi_{i}=70$ for GSI $=45$ are larger for higher values of the angle $\Theta$. Overall, the increase in the value of GSI for a given value of $\Theta$ is accompanied by an increase in the value of the angle $\varphi_{i}$. Differences in cohesion for $G S I=70$ in comparison with the $G S I=45$ decreases with the increase in the angle $\Theta$. Cohesion for an angle $\Theta=0^{\circ}$ and the $G S I=70$ has a value of approximately $18.9 \%$ greater than for $G S I=45$, while for an angle $\Theta=60^{\circ}$ the cohesion value for $G S I=70$ is only higher by about $8.3 \%$ than the value of cohesion for $G S I=45$.

\section{CONCLUSION}

The relation of the generalised Hoek-Brown failure criterion to stress state invariants makes it possible to take into account the impact of mean stress and the Lode angle on the strength parameters of rock mass that meets this criterion, i.e., cohesion, internal friction angle and global strength to the uniaxial compressive strength.

The calculations have shown that the internal friction angle of the rock decreases exponentially with increasing hydrostatic pressure, and increases the cohesion with an increase in hydrostatic pressure. The global uniaxial compressive strength of the rock mass that meets the generalised Hoek-Brown criterion increases non-linearly with increasing hydrostatic pressure.

The rate of change of the analysed parameters with increasing hydrostatic pressure is greater for good quality rock mass (meaning higher GSI values).

Global uniaxial compressive strength of the rock mass is greatest when the stress state is triaxial compression $\left(\Theta=0^{\circ}\right)$. The same statement applies to cohesion. On the other hand, the angle of internal friction is greatest when the stress state is triaxial extension $\left(\Theta=60^{\circ}\right)$. The effect of the Lode angle is smaller for a weaker rock mass (lower value of $G S I$ ).

The dependence of cohesion, friction angle and of the global compressive strength of the rock mass on the hydrostatic pressure and the Lode angle turns out to be more important for good quality rock mass.

\section{REFERENCES}

[1] BALMER G., A general analytical solution for Mohr's envelope, American Society of Testing Materials, 1952, 1260-1271.

[2] Brady B.H.G., Brown E.T., Rock Mechanics, 2nd ed., Chapman \& Hall, London, 1993.

[3] Chen W.F., Han D.J., Plasticity for Structural Engineers, J. Ross Publishing, New York, 2007.

[4] Duffy S.F., Modeling Stress Strain Relationships and Predicting Failure Probabilities for Graphite Core Components, Project No. 09-838, Cleveland State University, Ohio, 2013.

[5] HoEK E., Brown E.T., Empirical strength criterion for rock masses, Journal of Geotechnical Engineering Division, ASCE 106(GT9) 1980, 1013-1035. 
[6] Hoek E., Brown E.T., Practical estimates of rock mass strength, International Journal of Rock Mechanics and Mining Sciences, 1997, Vol. 34, No. 8, 1165-1186.

[7] HoEK E., Rock mass properties for underground mines, [in:] W.A. Hustrulid, R.L. Bullock (eds.), Underground Mining Methods: Engineering Fundamentals and International Case Studies, Littleton, Colorado: Society for Mining, Metallurgy, and Exploration (SME), 2001.

[8] Hoek E., Carrnza-Torres C., Corkum B., Hoek-Brown failure criterion - 2002 edition, Proc. NARMS-TAC Conference, Toronto, 2002, 267-273.

[9] IZBICKI R.J., Mróz Z., Metody nośności granicznej w mechanice gruntów i skat, PWN, Warszawa, 1976.

[10] Konderla P., Metoda elementów skończonych, teoria i zastosowania, Oficyna Wydawnicza Politechniki Wrocławskiej, Wrocław, 2007.

[11] KWAŚNIEWSKI M., Zachowanie się skat izo- $i$ anizotropowych $w$ warunkach trójosiowego ściskania, Zeszyty Naukowe Po- litechniki Śląskiej seria Górnictwo zeszyt 247. Wydawnictwo Politechniki Śląskiej, Gliwice, 2002.

[12] LEE Y.-K., CHOI B.-H., Equivalent Friction Angle and Cohesion of the Generalized Hoek-Brown Failure Criterion in terms of Stress Invariants, Tunnelling and Underground Space, 2010, Vol. 22, No. 6, 462-470.

[13] MoGi K., Effect of the triaxial stress system on fracture and flow of rock, Physics of the Earth and Planetary Interiors, 1972, Vol. 5, 318-324.

[14] MoGi K., Flow and fracture of rocks under general triaxial compression, Proc. 4th Int. Congr. on Rock Mechanics, Montreux, Balkema, Rotterdam, 1979, Vol. 3, 123-130.

[15] Nayak G.C., Zienkiewicz O.C., Convenient forms of stress invariants for plasticity, Proceedings of the ASCE Journal of the Structural Division, 1972, Vol. 98, No. ST4, 949-954.

[16] PATERSON M.S., Experimental rock deformation - the brittle field, Springer-Verlag, Berlin-Heidelberg-New York, 1978. 